\title{
COUPLING MECHANISM AND COUPLING DEGREE MEASUREMENT MODEL OF SHIPBUILDING INDUSTRY CLUSTER
}

\author{
SU Yi1 ${ }^{\mathrm{a}, \mathrm{b}}$, \\ Wang Fa-yin a, \\ AN Xiao-li ${ }^{\text {a }}$ \\ a) School of Economics and Management, Harbin Engineering University,P.R.China,150001 \\ b) School of Economics and Management, Tsinghua University,P.R.China, 10010
}

\begin{abstract}
This article was aimed to analyse the working condition of the coupling mechanism in Chinese shipbuilding industry cluster. Literature review was conducted to unveil the coupling mechanism of shipbuilding industry cluster, providing analysis of the present development of shipbuilding industry. A theoretical model was proposed by using the efficacy function and the capacity of the coupling coefficient while measuring the coupling of the shipbuilding industry cluster. Four coupling characteristics were found including relevant, systemic, diversity, and collaborative in the shipbuilding industry cluster. The shipbuilding industry cluster has two levels of coupling mechanism including the core layer coupling mechanism and the support layer coupling mechanism respectively. The improvement through coupling the core layer, support layer, and the coupling between two levels, is an effective way to achieve long-term stable development in Chinese shipbuilding industry cluster.
\end{abstract}

Keywords: coupling mechanism, coupling degree measurement model, shipbuilding industry cluster

\section{INTRODUCTION}

Chinese Shipbuilding Industry is the supporting industry of Chinese maritime transportation, ocean development and national defense construction, and strategic industry of combination of military and civilian. It has important significance to the national defense capability and the national economic growth. The construction of shipbuilding industrial cluster is an effective way to enhance the competitiveness of shipbuilding industry, and the appropriate coupling mechanism can make positive synergy effect on shipbuilding industry cluster. The industrial clusters of shipbuilding industry can take appropriate measures to improve the coupling degree to make the cluster maintain high coupling operation in a state of highly efficient operation, and make greater contribution to military and civilian. Shipbuilding industry cluster is an effective way for the development of shipbuilding industry as a strategic tool (Huang, 2006)[1]. Scholars focus on the studies on development elements (Cao and Liu, 2007)[2], development models (Tao and Yang, 2007; $\mathrm{Li}, 2008 ; \mathrm{Hu}$ and $\mathrm{Yu}, 2013)[3-5]$, the formation mechanism of shipbuilding industrial cluster (Tao, 2005; Zhao, 2007; Wang, 2010)[6-8], and the life cycle of South Korea's shipbuilding industry cluster (Shin et al., 2011)[9], shipbuilding industry cluster development theoretical model (Zong, 2013)[10], development opportunities and challenges of shipbuilding industry cluster (Zhang and Zeng, 2014)[11], etc. However, the literatures rarely involve the study of the complex mechanism of the shipbuilding industry cluster. The coupling theory provides a new theoretical support for this field of research. 
The coupling theory is applied to the study of the complex relationships within the systems, which is mainly used in manufacturing industry and other related fields. Li and Li (2005) presented that the equipment manufacturing industry cluster coupling contains three layers coupling mechanisms, namely the manufacturing enterprise's coupling mechanism, coupling mechanism of industry cluster and regional social network coupling mechanism, proposed the coupling degree model of equipment manufacturing industry cluster, analyzed the influence factors of equipment manufacturing industry cluster coupling degree and coupling mechanism, and finally made empirical analysis on Shenyang equipment manufacturing industry cluster[12]. Ruan and Zuan (2010) put forward the coupling degree model of manufacturing industry cluster, and made empirical analysis of the coupling degree on Qingdao manufacturing industry cluster[13]. Yuan et al. (2012) divided the network structure of the manufacturing industry into core manufacturing layer, industry matching layer, service support layer and analyzed coupling mechanism among layers[14]. Fu et al. (2012) made the research on the coupling of multiple wastewater using network design to achieve agile manufacturing[16]. Du et al. (2012) established the coupling coordination model about the industrial technology innovation ability. The model mainly includes three basic parts, the efficiency function, the coupling degree model and the evaluation index system. This coupling coordination model was used to evaluate whether the coal resource cities should develop some leading industries, and took Qitaihe as an example[17].Liu and Sun (2014) established the coupling degree measurement model of knowledge innovation and technology innovation in high-end equipment manufacturing industry, and proved the validity of the coupling degree measure model from the empirical point of view[15]. Zou et al. (2014) analyzed the development trend of the equipment manufacturing industry in Liaoning by using factor analysis method, and proposed the coupling development "Trilogy" of technology innovation and technological upgrading of Liaoning province equipment manufacturing industry combined with technological innovation and technological upgrading coupling improvement mechanism, respectively, exploration and development model, the leading domestic development model and international development model[18].The research of the coupling mechanism and coupling degree measurement model of shipbuilding industry cluster can provide theoretical guidance and decision-making basis for the industrial cluster of shipbuilding industry, which has important significance to both theoretical and practical development.

\section{DEVELOPMENT STATUS QUO OF CHINESE SHIPBUILDING INDUSTRY}

\section{CHINA REMAINED THE WORLD'S LARGEST SHIPBUILDING COUNTRY}

The data of Figure 1 and 2 are obtained from China Association of the National Shipbuilding Industry Website. The new orders of China, South Korea, and Japan already occupied more than $90 \%$ of the world shipbuilding total completion. The market share of China was more than $45 \%$ both in the year of 2013 and 2014, followed by South Korea and Japanese with the market share of about $30 \%$ and $20 \%$ respectively.

The new received orders in China kept the world's first in 2013 and 2014. From the perspective of market share, China, South Korea and Japan are the world shipbuilding countries led by China. China's shipbuilding industry development is quite superior and stability.

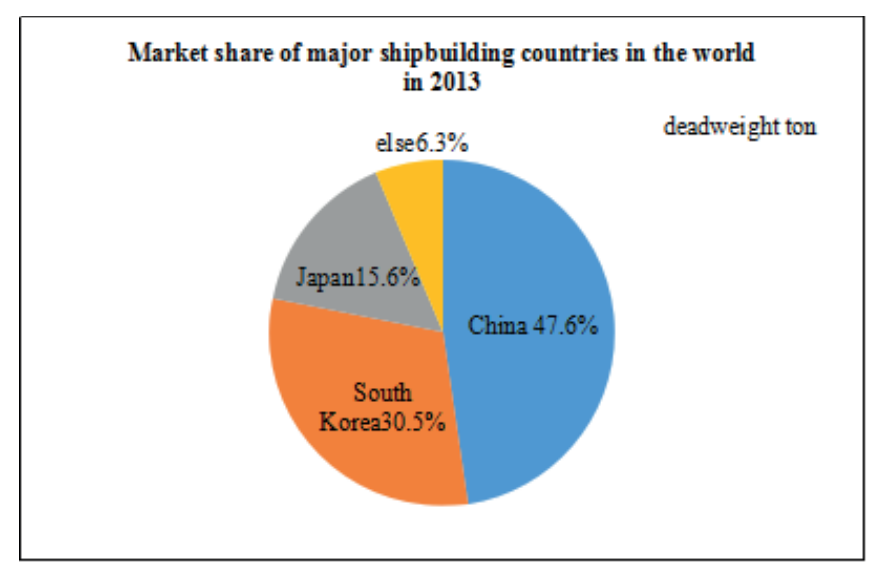

Fig.1. Market share of major shipbuilding countries in the world in 2013

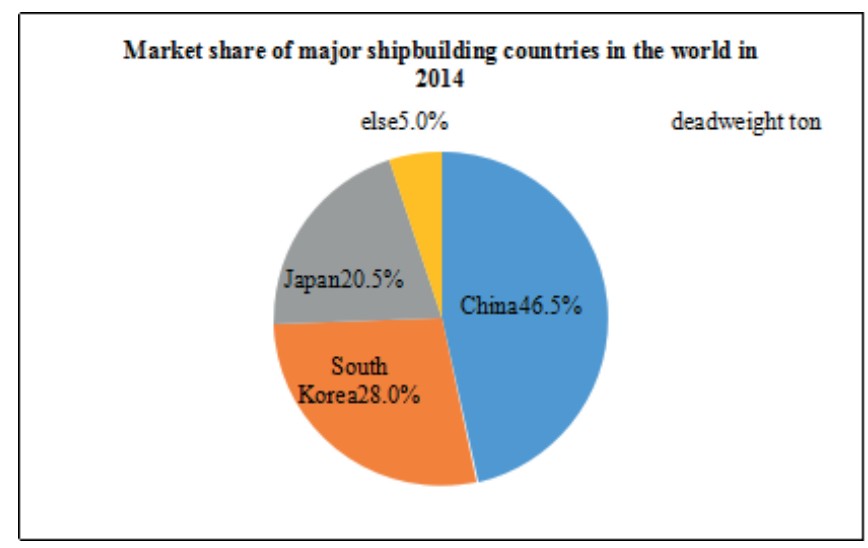

Fig.2. Market share of major shipbuilding countries in the world in 2014

\section{THE THREE MAJOR INDICATORS OF CHINESE SHIPBUILDING INDUSTRY ARE SHOWING AN OVERALL UPWARD TREND}

From 2001 to 2014, China's annual shipbuilding output, the new received orders, the overall holding orders had showed a rising trend, and reached the highest value in 2012, 2007 and 2008, respectively. China's annual shipbuilding output had been declining in the last three years, but the degree of declining has slowed. The number of new received orders had increased significantly, and then fell slightly. China's annual shipbuilding output, the new received orders, and the overall holding orders had been showing a fluctuation states, however the general trends are still upward. 


\section{INDUSTRIAL CONCENTRATION HAS BEEN INCREASED, AND THE COMPREHENSIVE STRENGTH HAS BEEN GREATLY IMPROVED}

In the year of 2014, there were more than 90 percent orders has been completed in the three major shipbuilding bases, which were in the place of the Bohai Bay region, Yangtze River Delta and Pearl River Delta. The concentration degree of top 10 enterprises, top 20 enterprises and top 30 enterprises was up to $50.6 \%, 71.6 \%, 83.8 \%$, respectively, which increased $3.2 \%, 5.9 \%$ and $7.4 \%$ respectively comparing to the year of 2013. This means the degree of industrial concentration has been significantly improved. There has been formed a group of key enterprises in China, and four of them are the world's top ten enterprises, in terms of new orders. We can obtain that Chinese shipbuilding enterprises' market competitiveness and the international status had been improved.

\section{MARKET DEMAND IS NOT BALANCED, AND THE DEVELOPMENT POTENTIAL IS SLIGHTLY INADEQUATE}

In the year of 2014, China's new receive orders quantity maintained a high level, which was about 60 million deadweight tons. The quantity of new receive orders was showing a quarterly decline trend, which was 25 million deadweight tons, 14 million deadweight tons, 11 million deadweight tons and 7 million deadweight tons, from first quarter to the fourth quarter, respectively. Except the first quarter, the situation of shipbuilding enterprises had deteriorated significantly in the year of 2014. The main reason is as following: first of all, shipping market supply and demand contradictions problems have not been fundamentally resolved, and the order quantity is gradually reduced. Secondly, as a significant reduction in international oil prices, which dampened the enthusiasm of the enterprise to manufacture energy-saving ships, and postponed dismantling of old ships, the market demand for new ships continued to decrease. In recent years, the Chinese shipbuilding outputhas reached 20 million tons. Facing the depresseding market, China's shipbuilding industry capacity utilization efficiency is not high, and does not reach a reasonable level of the industry.

\section{THE COUPLING CONNOTATION AND CHARACTERISTICS OF SHIPBUILDING INDUSTRY CLUSTER}

\section{THE COUPLING CONNOTATION OF SHIPBUILDING INDUSTRY CLUSTER}

As a typical large-scale equipment manufacturing industry, shipbuilding industry enterpriseshave many characteristics such as long industrial chain involved and high requirements for supporting industry [4].A mature shipbuilding industry cluster should include the shipping core manufacturing enterprises, the ship supporting enterprises, the ship parts production enterprises, and the service oriented institutions.
Unique symbiotic cluster of shipbuilding industry enterprises was formed through the exchange of knowledge, information, human resources, equipment and capital of each subject in the cluster. On one hand, from the ecological point of view, the shipbuilding industry cluster is a industry species ecological system; on the other hand, from the innovation economics point of view, shipbuilding industry cluster is a special kind of regional innovation system[19].This paper argues that the shipbuilding industry cluster refers to taking ship manufacturing enterprises as the center, and united the related enterprises or organizations of ship industry, such as: supporting enterprises, universities, research institutions, vocational training institutions and shipbuilding industry association, gathering together to form an organic system in a particular geographic location [8][20]. The industry cluster, which has complete industrial structure, robust support system, can be formed through specialization and depth cooperation of subjects within the cluster. Initially coupling is a physical concept, which has been widely used in the field of system science and social sciences. The concept of coupling is used to explore or describe the relationship, mutual influence and common cooperation and evolution process of various systems. In physics, coupling refers to the phenomenon that two or more than two of the circuit elements or the input and output of the electrical network are closely matched with each other, and the transmission of energy from one side to the other side through the interaction. In this article, the coupling is defined as a dynamic relationship formed by positive interaction, matching and coordination among system elements or subsystems to achieve the coordinated development. The coupling of Chinese shipbuilding industry cluster is a kind of dynamic relationship and synergistic action process among the related enterprises and organizations of shipbuilding industry. The coupling of shipbuilding industry cluster is not only coordination among the agents, but is also on collaborative development, so as to achieve the purposes, such as complementary advantages, mutual promotion and coordinated development.

\section{THE COUPLING CHARACTERISTICS OF SHIPBUILDING INDUSTRY CLUSTER}

Shipbuilding industry cluster has the characteristics of relevance, systematic, diversity, collaborative etc. Firstly, correlation. The coupling agents including core ship manufacturing enterprises, the ship supporting enterprises, the ship parts production enterprises, and the service organizations are interrelated and interact with each other. Shipbuilding industry cluster is not a closed static system. Obviously, Chinese shipbuilding industry cluster has the prerequisites for application of coupling theory. Secondly, systematic. The main subjects or elements in the coupling system form a new system through cooperating with each other according to certain rules. The main bodies of Chinese shipbuilding industry cluster form the new system of shipbuilding industry cluster through cooperating with each other according to the rules and regulations, such as cooperation contract, contract etc. Thirdly, diversity. Each 
coupled subsystem has its own organizational characteristics. The links between the elements of the subsystems are complicated, which constitute a variety of coupling modes. Each subject of shipbuilding industry cluster has its own organization and management mode and characteristics, so the links of enterprises and support service agencies are very complex, and the relationship between them is dynamic. Finally, collaborative. The coupled subsystems in shipbuilding industry cluster interact with each other through the way of complementary advantages to achieve the collaborative development of the entire system [21].

\section{THE COUPLING MECHANISM OF SHIPBUILDING INDUSTRY CLUSTER}

Large ship manufacturing enterprises are the core of agglomeration of Chinese shipbuilding industry cluster, and a series of related businesses(ship matching enterprises, ship parts production enterprises and shipbuilding supporting enterprise) and service organizations (such as scientific research institutions, intermediary institutions, government agencies, educational institutions, and shipbuilding industry association) are derived from the large ship manufacturing enterprise. These service institutions provide the related services, such as technical, information, policy guidance and coordination for the cluster. Chinese Shipbuilding Industry Cluster coupling structure contains two levels of coupling mechanisms: the core layer coupling mechanism, and the support layer coupling mechanism[12]. The coupling of the shipbuilding industry cluster is the complex combination of the two levels of coupling mechanisms rather than a simple superposition. The two coupling layers are closely linked to each other based on knowledge sharing and economic transactions, but independent of each other. The coupling dynamics of one level will have an effect on the other coupling layer, thus affecting the overall function of the cluster. A positive effect is produced by the good coupling of two levels, to promote the formation of a high coupling degree of the entire cluster, so as to maintain sustainable competitiveness.

\section{COUPLING MECHANISM OF CORE LAYER}

The core layer coupling mechanism is mainly the coupling of the core ship manufacturing enterprises, the ship matching enterprises, the ship spare parts manufacturing enterprises and the shipbuilding supply enterprises. In this coupling layer, the cooperation of the enterprises is not only between supply and demand, but the matching of the upstream and downstream enterprises in the product, service and manpower, etc, based on the complete vertical industrial chain. Industrial connection is a prerequisite for the coupling of industry cluster, and the information flow in unobstructed and timely manner are the conditions of realizing the benign coupling. Shipbuilding industry cluster is a typical vertical industry chain agglomeration model, which is longer, involving a wide range of services, with high requirements for matching services. The ship spare parts manufacturing enterprises, the ship matching enterprises, and the ship core manufacturing enterprises are closely linked to form a vertical industrial chain.

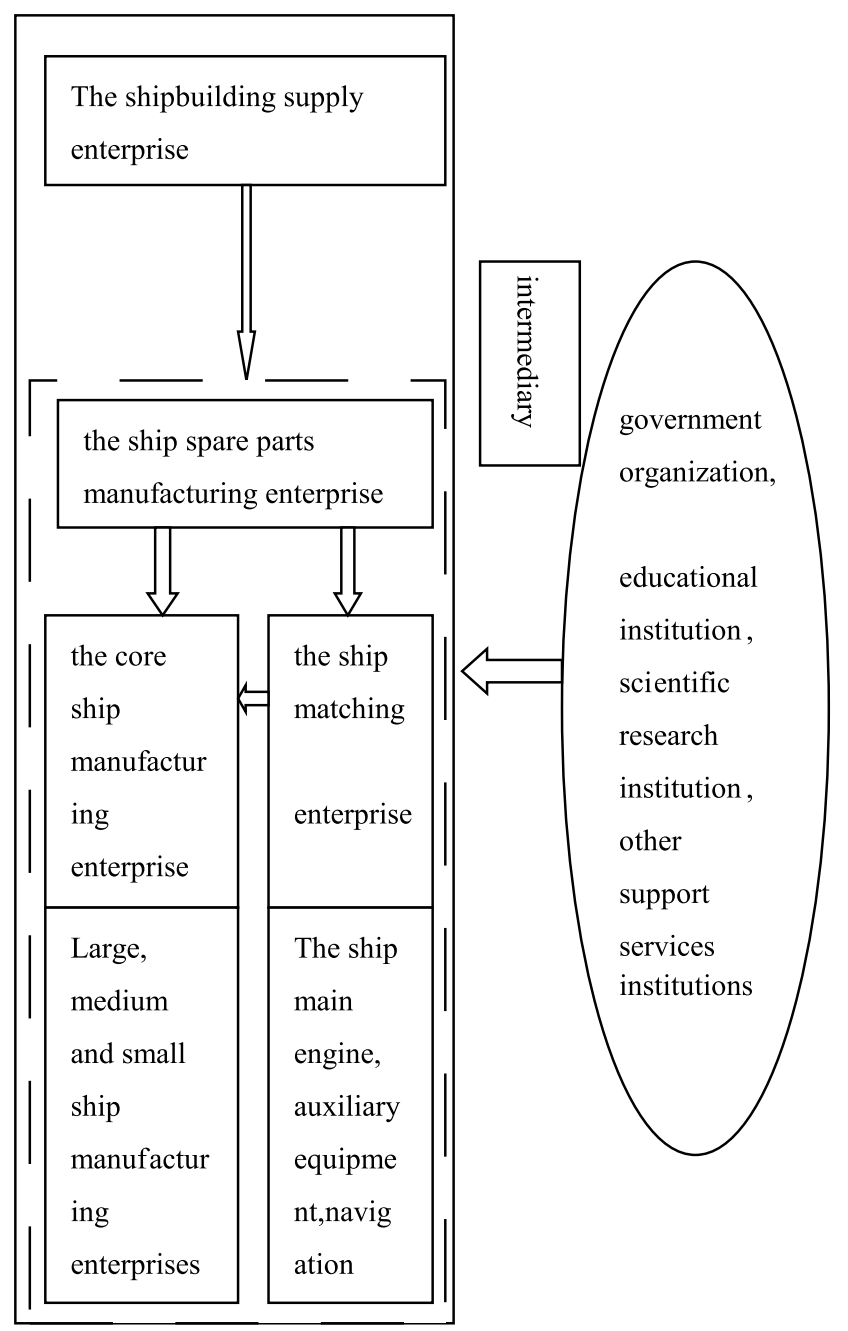

Fig.3. The coupling structure of shipbuilding industry cluster core layer

The main contents of the core layer coupling mechanism are ship manufacturing enterprises, which are the core of the shipbuilding industry cluster and play the role of the components supplied by the supporting enterprises to be assembled into the ship. The matching enterprises and the ship spare parts manufacturing enterprises provide the ship core manufacturing enterprises with spare parts and necessary components of the ship. Of course, the ship spare parts production enterprises also provide spare parts for the ship matching enterprises. Shipbuilding supply enterprises provide the cores of ship manufacturing enterprises, the ship matching enterprises and ship spare parts production enterprises with all kinds of raw materials for shipbuilding. These adaptation stages are the initial stage of coupling, and the closely and efficiently cooperation and interaction among the enterprises are the key points. Each enterprise needs follow-up and support of other links as key link in the vertical industry chain, and the benign interaction among enterprises to produce the adhesive effect, so as to achieve the coordinated 
development and the coupling. Good coupling mechanism can promote the formation of positive coupling effect bundle. The positive effect of the coupling effect bundle is amplified to achieve positive cycle.

\section{COUPLING MECHANISM OF SUPPORT LAYER}

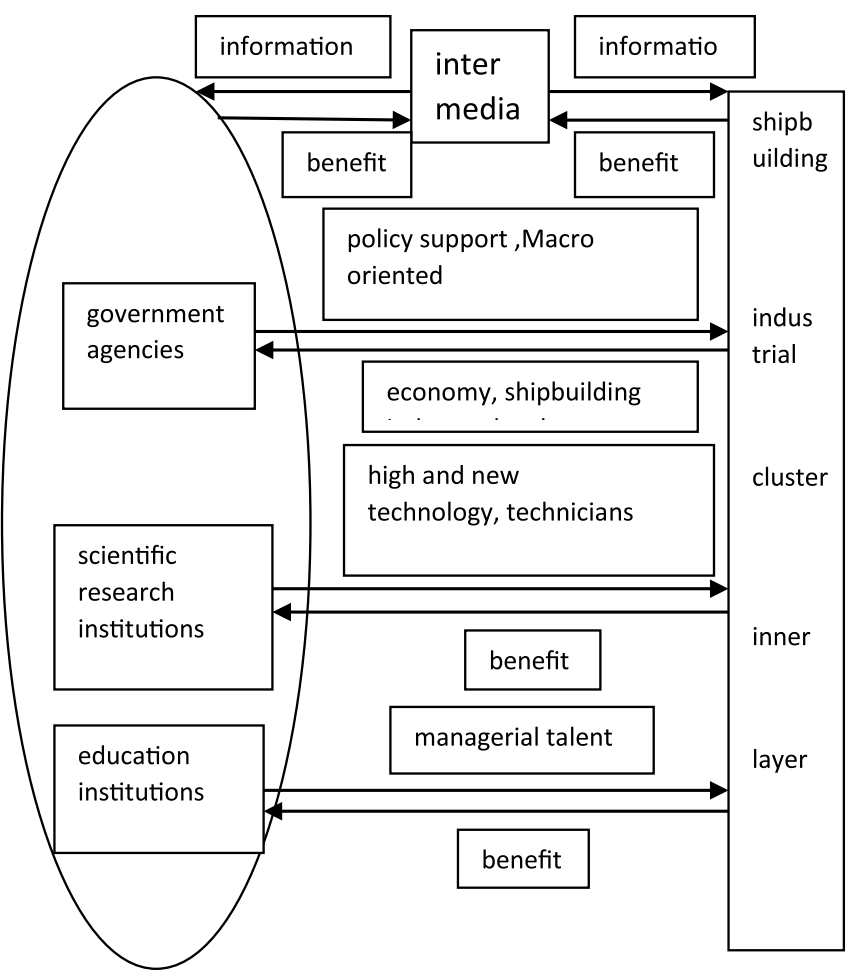

Fig.4 .The support coupling layer structure of shipbuilding industrial cluster

Support coupling mechanism is also the outer coupling mechanism, mainly provides technology information, resource, policy guidance and other services for shipbuilding industry cluster. The coupling layer mainly includes the relation and coupling between some support service institutions and the inner cluster. The inner cluster includes the shipping core manufacturing enterprises, the ship matching enterprises, the ship spare parts production enterprises and the shipbuilding supply enterprises. This coupling layer is important, but can easily be neglected. Support service institutions, which are parts of support coupling layer, include government agencies, intermediary institutions, scientific research institutions, education institutions, financial institutions and shipbuilding industry association, etc. In general, these support service institutions support cluster inner layer. Support coupling layer structure is as follows.

The main contents of support layer coupling mechanism are government agencies involving in shipbuilding industrial cluster coupled by providing policy support, macro-environment creation, etc. for cluster inner layer. Government agencies play a guiding role on the behavior of all the subjects in the cluster inner layer by industrial preferential policies, tax policies to bring the cluster to benign coupling. Intermediary agencies provide information services for the cluster, playing the role of middle bridge and avoiding low coupling degree of cluster caused by the non-smooth information. Scientific research institutions include universities and research institutes, which are the most important innovation institutions of knowledge and technology. Shipbuilding industry cluster inner layer can cooperate with scientific research institutions, such as forming the Research Alliance to continue to learn new technologies, to absorb shipbuilding talents. Scientific research institutions become the birthplace of the hightech and technical talents of the cluster inner layer in this way. Education and training institutions train managers, so cluster coupling degree is improved by the managers by making the scientific management more effectively in the cluster inner layer. Financial institutions provide funding for enterprises. Shipbuilding industry associations offer a variety of social services for shipbuilding industry cluster, and maintain the legitimate rights of interests of the member units and the industry. The overall effect is much greater than their respective effect, resulting in efficiency overflow proliferation and positive effect on the whole cluster, thus forming a virtuous circle, expanding the overall positive effect of the cluster, so as to achieve benign coupling by support service institutions coordinating with cluster inner layer, and producing synergistic effect in dynamic interaction.

\section{CONSTRUCTION OF COUPLING DEGREE MEASUREMENT MODEL OF SHIPBUILDING INDUSTRY CLUSTER}

Previous research illustrates the coupling mechanism of shipbuilding industry cluster. In reality, it is necessary to measure the coupling degree of shipbuilding industry cluster scientifically in order to clear the coupling condition of shipbuilding industrial cluster. Then relevant institutions can take pertinent measures to improve cluster coupling degree. Construction process of coupling degree measurement model of shipbuilding industry cluster is as follows.

\section{EFFICIENCY FUNCTION OF SHIPBUILDING INDUSTRY CLUSTER}

Set variable $(i=1,2, \ldots, n)$ is the order parameter of the shipbuilding industry cluster. The core ship manufacturing enterprise, the ship matching enterprise, the ship spare parts manufacturing enterprise, the shipbuilding supply enterprise, and support service institution are the five order parameters. $u_{i j}$ is the $j$-index of $i$-parameter, the value is $X_{i j}(i=1,2, \ldots, n)$. $\mathrm{A}_{\mathrm{ij}}, \mathrm{B}_{\mathrm{ij}}$ are the upper and lower limits of order parameter of shipbuilding industry cluster steady state. And efficiency function of the core ship manufacturing enterprise, the ship matching enterprise, the ship spare parts manufacturing enterprise, the shipbuilding supply enterprise, and support service institution orderly to shipbuilding industrial cluster system can be expressed by:

$$
u_{i j}=\left\{\begin{array}{l}
\left(X_{\mathrm{ij}}-B_{i j}\right) /\left(A_{i j}-B_{i j}\right) \\
\left(A_{i j}-X_{i j}\right) /\left(A_{i j}-B_{i j}\right)
\end{array}\right.
$$

$\mathrm{u}_{\mathrm{ij}}$ has a negative effect $\mathrm{u}_{\mathrm{ij}}$ has a positive effect 
The $u_{i j}$ is the efficiency contribution size of variable $X_{i j}$ to the system. $\mathrm{u}_{\mathrm{ij}}$ represents the satisfaction degree of each index reaching the goal, $\mathrm{u}_{\mathrm{ij}}$ is between 0 and 1 , reaching to 0 for the most unsatisfied, closing to 1 for the most satisfactory. The core ship manufacturing enterprise, the ship matching enterprise, the ship spare parts manufacturing enterprise, the shipbuilding supply enterprise and support service institution are mutually connected and influenced subsystems, the total contribution of each index to subsystems is achieved by integrated method, and the linear weighted method is generally used[22].

$$
\begin{aligned}
& u_{i}=\sum_{j=1}^{m} \lambda_{i j} \mu_{i j} \\
& \sum_{j=1}^{m} \lambda_{i j}=1
\end{aligned}
$$

$u_{i}$ is the contribution of subsystem to total system order degree. $m$ is the number indicators of subsystem, $\lambda_{\mathrm{ij}}$ is index weights. The weights of each index can be determined by analytic hierarchy process and entropy weight method[22] [23].

\section{COUPLING DEGREE FUNCTION OF SHIPBUILDING INDUSTRY CLUSTER}

The calculation of the coupling degree of shipbuilding industry cluster draw lessons from the concept of capacity coupling and capacity coupling coefficient model in physics[24]. In this paper, it is extended to the coupling degree measurement model of multiple systems.

$$
C_{n}=n\left\{\left(u_{1} \cdot u_{2} \cdots u_{n}\right) / \prod\left(u_{i}+u_{j}\right)\right\}^{\frac{1}{n}}
$$

According to the above equation, the core layer consists of four sub-systems, namely the core ship manufacturing enterprise, the ship matching enterprise, the ship spare parts manufacturing enterprise, the shipbuilding supply enterprise. Support layer consists of five subsystems, namely the core ship manufacturing enterprise, the ship matching enterprise, the ship spare parts manufacturing enterprise, the shipbuilding supply enterprise and support service institution. The core layer coupling degree measurement model and the support layer coupling degree measurement model are constructed with subsystem number instead of $\mathrm{n}$ of the formula. The value of $C$ is between 0 and 1,1 represents subsystem coupled with maximum degree and the coupling condition of subsystems benign. 0 represents subsystems coupled with minimum degree, and the subsystems are independent.

Coupling degree $\mathrm{C}$ is an important parameter to judge the coupling state of the subsystems, but it is difficult to reflect the overall effect of the cluster coupling in some cases, especially in the cluster contrast study. Due to the development strategy, the characteristics of each shipbuilding industry cluster are different. For example, development stages of cluster $\mathrm{A}$ and cluster B are different, but the coupling degree is the same. Therefore, it is obviously not a good reflection of the shipbuilding industry cluster synergy and the overall effect only using the coupling degree to evaluate the development of the cluster. In this case, the significance of conclusion by using the coupling degree to the development of cluster is not obvious. The modified coupling degree measurement model of shipbuilding industry cluster is[25-27]:

$$
\left\{\begin{array}{l}
C^{\prime}=(C \cdot T)^{\frac{1}{2}} \\
T=a u_{1}+b u_{2}+c u_{3} \cdots
\end{array}\right.
$$

where, $\mathrm{C}$ is coupling degree; C' is modified coupling degree; $\mathrm{T}$ is subsystem comprehensive harmonic index of shipbuilding industrial cluster, which reflects the overall synergistic effect of shipbuilding industrial cluster; $a, b, c$, etc. are undetermined coefficients, which can determined by absorbing the experts' advice. The modified coupling is divided into four levels. Coupling layer of shipbuilding industrial cluster is in the low coordination coupling stage, if $0<C^{\prime} \leq 0.4$. Coupling layer of shipbuilding industrial cluster is in the moderate coordination coupling stage, if $0.4<C^{\prime} \leq 0.6$. Coupling layer of shipbuilding industrial cluster is in the high coordination coupling stage, if $0.6<\mathrm{C}^{\prime} \leq 0.8$. Coupling layer of shipbuilding industrial cluster is in the extreme coordination coupling stage, if $0.8<\mathrm{C}^{\prime} \leq 1$.

\section{CONCLUSIONS}

Through the review of the prior literature on the Chinese shipbuilding industrial cluster and manufacturing, this paper focuses on the current development of the Chinese shipbuilding industry and related concepts. The shipbuilding industrial cluster includes two basic coupling mechanism layers: the core layer and support layer on top of the prior papers, this paper developed a new coupling degree measurement model In order to achieve the long-term stable development of the shipbuilding industry cluster, the following aspects were proposed.

First of all, the ship matching enterprises play an important role in the shipbuilding industry cluster. Accelerated development of matching industries is useful for improving the coupling degree of the core layer, promoting the development of the shipbuilding industry cluster. When the matching capacity cannot catch up with the development of the shipbuilding industry, the ship manufacturing enterprises will not carry out effective production activities, in other words, the core layer coupling degree of shipbuilding industry cluster is delayed by the supporting layer. The development of matching industries can be accelerated by implementing professional operation, e.g. establishing the main auxiliary instrument, machinery and other professional company; concentrating financial resources, material resources, manpower to engage in specialized production[6].Specialized production can be applied to improve the matching capacity of shipbuilding industry cluster, to promote the establishment of a good coupling mechanism. 
Secondly, the support layer coupling can be strengthened by enhancing the flow of knowledge and technological innovation of the shipbuilding industry cluster. As the current spillover of the Chinese shipbuilding industry is still at a lower level, the coupling degree of the support layer is restricted at relative lower level. It is obviously that the improvement of knowledge spillover of shipbuilding industry cluster can optimize the coupling mechanism of the cluster, and promote the development of coupling of shipbuilding industry. Technology innovation can save the cost of shipbuilding for the cluster, but also can make up the in shortage of raw materials in shipbuilding, so that the cluster is more competitive. The knowledge creation and flow can be strengthened through enhancing cooperation of the industry and universities, increasing the flow of talents and enhancing the sharing degree of infrastructure facilities[3].

Thirdly, the two level coupling state of cluster can be promoted by taking measures together and developing producer service industry. Chinese shipbuilding industry can better achieve structural adjustment, and the cluster can better maintain a good coupling state by speeding up the development of producer service industry. Efficient logistic services, perfect marketing and after-sale service network systems are good signs of the core layer coupling status, sound financial services system is a good performance of the support layer coupling status. Accordingly, the coupling degree of the two layers can be improved by the following ways, so that the cluster can maintain a high degree of coupling status. First, the cluster can establish information and intelligent logistic service systems by making full use of modern information technology. Second, it can build brands, and improve market share by establishing and improving the global after-sale services and marketing network systems. Third, Cluster can improve the construction of the ship financial services system to provide better financial support for the development of the shipbuilding industry cluster by strengthening cooperation with domestic and foreign financial institutions, developing multi-channel financing, and improving financing means.

Coupling structure of shipbuilding industry cluster is complicated, this research puts forward the coupling mechanism of the shipbuilding industry cluster, and coupling measurement model was established. However, further empirical research needs to be carried out. The coupling theory will be applied to the empirical research through field survey and secondary data collection based on this research in the future.

\section{ACKNOWLEDGEMENTS}

The authors thank reviewers for their insightful comments. This work was supported by National Natural Science Foundation of China(71403066), Doctoral Fund of Ministry of Education of China(20122304120021), China Postdoctoral Science Foundation(2013T60351), Heilongjiang Province Postdoctoral Start Foundation (LBH-Q13050), the Special Foundation of Central Universities Basic Research Fee (HEUCF140907).

\section{REFERENCE}

1. Huang Jin. Chinese shipbuilding industry cluster development stratify[D].Hunan University.2006.(in Chinese)

2. Cao Yousheng,Liu Xisong. Research on elemental factors and countermeasures in promoting cluster of China shipbuilding industry[J].Ship Building of China,2007(3):9195. (in Chinese)

3. Tao Yonghong,Yang Haisong. On development mode and strategy of shipbuilding industrial cluster in Yangtze River Delta[J].Journal of Jiangsu University of Science and Technology(Social Science Edition), 2007(6):33-38. (in Chinese)

4. Li Hao. Research on the Yangtze River Delta ship industry cluster development[D].Lanzhou University.2009. (in Chinese)

5. Hu Wei,Yu Yingying. Research on the development model and strategic of Wuhu ship industrial cluster[J].Machine Design and Manufacturing Engineering,2013(3):22-25. (in Chinese)

6. Tao Yonghong. Formation mechanism and developments research of the shipbuilding industry cluster based on The Symbiosis Theory[D].Nanjing University of Science \& Technology.2005. (in Chinese)

7. Zhao Xin. The research on Chinese shipbuilding industry cluster[D].Dongbei University of Finance and Economics.2007. (in Chinese)

8. Wang Lei. The Research on formation and development of the shipbuilding industrial clusters in Yangtze River Delta[D].Shandong University.2010. (in Chinese)

9. Shin,Dong-Ho,Hassink,Robert. Cluster life cycles: the case of the shipbuilding industry cluster in South Korea[J]. Regional study.2011,45(10):1387-1402. (in Chinese)

10. Zong Shengchun. Research on Yantai shipbuilding industrial cluster and its development strategy[D].Ocean University of China.2013. (in Chinese)

11. Zhang Mudan,Zeng Yihui. The development thoughts and countermeasures on the shipbuilding industry cluster in the ecological economic zone of Dongting Lake[J]. Business,2014(2):301. (in Chinese)

12. Li Kai,Li Shijie. Coupling structure of equipment manufacture industrial clusters: a new view on the industrial clusters[J].China Industrial Economy, 2005(2):5157. (in Chinese) 
13. Ruan Yanyan,Qi Zhenfa. The study of coupling degree of manufacturing clusters[J].Journal of Shandong University of Technology(Natural Science Edition),2010(11):107-110. (in Chinese)

14. Yuan Yijun,Ren Huanhuan,Zhang Mengmeng. Coupled network analysis and upgrading path of equipment manufacturing industry[J].Science \& Technology Progress and Policy,2012(5):59-61. (in Chinese)

15. Liu Weiwei,Sun Ru. Research on coupling degree measurement between knowledge innovation and technological innovation of High-End equipment manufacturing enterprises[J].Science of Science and Management of S.\& T., 2014(7):17-22. (in Chinese)

16. Jie Fu,Tianxing Cai,Qiang Xu. Coupling multiple waterreuse network designs for agile manufacturing[J]. Computers and Chemical Engineering.2012,45(12):62-71.

17. Du Jiming,Yu Bo, Yao Xilong. Selection of leading industries for coal resource cities based on coupling coordination of industry's technological innovation[J].International Journal of Mining Science and Technology.2012,22(3):317-321.

18. Zou Hua,Sun Jian,Sunjinliang. Research on the coupling development of technology innovation and technology upgrading of equipment manufacturing industry-a case study of Liaoning[J].Science \& Technology Progress and Policy, 2014(8):76-79. (in Chinese)

19. Wu Dejin. Organizational nature of industrial cluster:property and connotation[J].China Industrial Economy, 2004(7):14-20. (in Chinese)

20. Wang Hui,Zhang Guangming. Analysis of shipbuilding supply chain structure characteristics and competitive advantage in shipbuilding industry cluster[J].Marine Technology,2007(1):4-6. (in Chinese)

21. Li Yong. On Coupling mechanism of regional industry[J]. Business Economy,2010(5):31-34. (in Chinese)

22. Qiu Guodong, Ma Qiaohui. The endogenous coupling mechanism of technological innovation and institutional innovation: the secret of corporation growth-a case study of Geely and Hyundai[J].China Soft Science,2013(12):94-113. (in Chinese)

23. Xu Yulian,Wang Yudong,Lin Yan. Research on coupling coordinated degree evaluation of regional sci-tech innovation and sci-tech finance[J].Science of Science and Management of S.\& T., 2011(12):116-122. (in Chinese)

24. Varile. Dictionary of Physics (in Chinese)[M].Beijing: Foreign Language Press,1996.
25. Kowalski, Jakub; Lesniewski, Wojciech; Litwin, Wojciech. Multi-source-supplied parallel hybrid propulsion of the inland passenger ship STAH Research work on energy efficiency of a hybrid propulsion system operating in the electric motor drive mode[J]. Polish Maritime Research, 2013, 20(3): 20-27.

26. Liu Yaobin,Song Xuefeng. Coupling degree model and its forecasting model of urbanization and ecological environment[J].Journal of China university of Mining \& Technology, 2005(1):91-96. (in Chinese)

27. Jiang, Haibo; Tang, Kai; He, Xinlin. Experimental Studies on Reduction of Evaporation from Plain Reservoirs in Drought Areas by Benzene Board Covering Technology[J]. Journal of Coastal Research, 2015, SI73: 177-182.

\section{CONTACT WITH AUTHOR}

\author{
SU Yi \\ School of Economics and Management, \\ Harbin Engineering University, \\ Harbin 150001, \\ P.R.China \\ School of Economics and Management, \\ Tsinghua University, \\ Tsinghua, 10010 \\ P.R.China, \\ E-mail: suyi@hrbeu.edu.cn
}

